\title{
STRAY CURRENTS ON DIRECT - CURRENT RAILWAYS IN SLOVENIA
}

DC stray currents are currents which do not flow through designed conductors but along the path of least resistance. These currents are very harmful to various metallic structures and lead to corrosion in the long term. The most significant sources of DC stray currents in Slovenia can be found in electrified railways using the direct current system of $3000 \mathrm{~V}$. Not all the return current can flow back to the rectifier substation through the rails but a high percentage of this current is dispersed in the earth, depending on conductive arteries. In some cases, these stray currents even cross a very winding railway line.

The Slovenian Railways have electrified a substantial part of their railway lines using the direct current system of $3000 \mathrm{~V}$. The complete $3000 \mathrm{~V}$ direct current overhead line system in Slovenia is being fed by 18 rectifier substations (ENP).

Key words: DC stray currents, electric traction, rails, rectifier stations, road metal, locomotives

\section{Introduction}

DC stray currents in the earth cause damage to metal structures. The possible sources of these currents in the earth are the following installations:

1. DC operated railways where rails are used as return conductors,

2. earthed DC installations with an operated circuit, earthed in several points.

Such installations are:

- overhead trolleybus networks with one pole earthed in several points or with one pole more than once connected to the return conductor of the tram network (rails),

- DC networks and DC industrial installations,

- DC telecommunication networks,

- Installations for protection against corrosion.

Installations, buried in the earth which are imperilled by DC stray currents, are:

1. metal pipelines,

2. metal cisterns,

3. metal constructions and concrete reinforcement

4 armoured cables,

5. earthings of power and telecommunication installations.

Electrified railways, operating in DC system of $3000 \mathrm{~V}$ where the total current flows through the return conductor (rail) are at present the main source of DC stray currents in Slovenia.

Return currents amount up to 2400 A depending on the number of consumers (electric locomotives).

\section{Calculation of stray currents on DC railways of $3000 \mathrm{~V}$}

In electric traction of $3000 \mathrm{~V}$ the traction vehicle receives its power supply from the rectifier substation through the overhead contact system (contact line). The circuit is closed through the electric locomotive and the rails back to ENP as shown in Fig. 1.

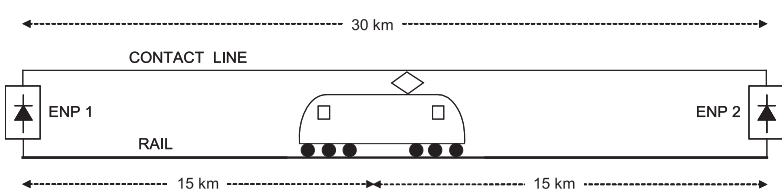

Fig. 1 Operating circuit of the electric traction vehicle

All ENP of Slovenian Railways operate in parallel, which means a two-way supply of the traction vehicle, which can be seen in Fig. 1. Consequently, the return current flows through the return rail back to ENP in both directions, to ENP 1 and to ENP 2. As the locomotive approaches ENP 2, the load of ENP 1 decreases. When the electric traction vehicle is very close to ENP 2, a minimal return current is still flowing in the direction of ENP 1.

One-way supply of the electric traction vehicle on Slovenian railways exists only at the exit of our electric traction system to the neighbouring countries, which use single-phase AC systems of electric traction (Austria and Croatia), and during accidental outages of ENP or during maintenance works.

Rails are laid over wooden or concrete sleepers on the road metal and represent at the same time the earthing electrode of the

\footnotetext{
* Bojan Cene

Ministry for Traffic, Ljubljana, Slovenija

E-mail: bojan.cene@gmail.com
} 
operational circuit of electric traction of the DC system of $3000 \mathrm{~V}$, which can be seen in Fig. 2.

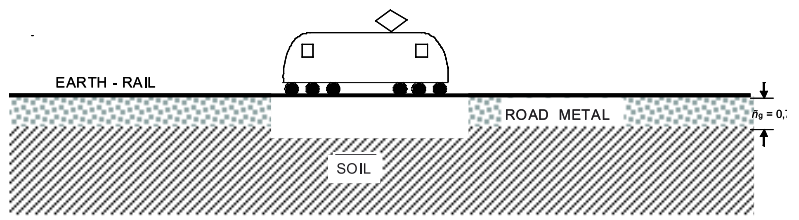

Fig. 2 Earthing of the operational circuit of electric traction

As can be seen in the figure, the rails are placed on a road metal, which is on average $0.7 \mathrm{~m}$ high. The road metal is spread on soil. This means the earthing electrode lies on non-homogeneous soil, whereby the road metal has a higher specific ohmic resistance than the soil. In that case, the earthing resistance of the total earthing system is calculated according to equation [1]:

$$
R_{o}=\frac{\rho_{g} \cdot h_{g}}{D^{2} \cdot \frac{\pi}{4}}+\frac{\rho_{z}}{2 \cdot D}(\Omega)
$$

where:

$R_{o}$ is the earthing resistance of the rail in $\Omega$,

$\rho_{g}$ is the specific resistance of crushed stone in $\Omega \mathrm{m}$,

$h_{g}$ is the height of road metal in $\mathrm{m}$,

$D$ is the diameter of earthing electrode in $\mathrm{m}$,

$\rho_{z}$ is the specific earth resistance in $\Omega \mathrm{m}$.

The earth electrode - rails, which represents a strip-type earth conductor, consist of two or more strips - the rails. Since the distance between the two strips - the rails is smaller than $5 \%$ of the length of rails, the following equation is valid for calculating the diameter of the equivalent plate [1]:

$$
D=1.13 \cdot \sqrt{S} \quad(\mathrm{~m})
$$

$S$ is the surface of earth electrode - rails, in $\mathrm{m}^{2}$

The surface of the earth electrode - rails is calculated according to the following equation [2]:

$$
S=a \cdot(n \cdot b) \quad\left(\mathrm{m}^{2}\right)
$$

\section{where:}

$n$ is the number of rails ( 2 rails for a single track line),

$a$ length of rails in $\mathrm{m}$

$b \quad$ width of rail base $=0.125 \mathrm{~m}$

Specific resistance of earthing electrode - rails per unit of length is calculated according to the following equation [3]:

$$
R_{t}=\frac{\rho_{t} \cdot L}{2 \cdot m \cdot A}(\Omega)
$$

where:

$\rho_{t}$ is the specific resistance of rails $=0.20 \Omega \mathrm{mm}^{2} / \mathrm{m}$,
$R_{t}$ is the specific resistance of earthing electrode - rails per unit of length in $\Omega / \mathrm{km}$,

$L \quad$ is the length of earthing electrode - rails in $\mathrm{m}$

$m$ is the number of tracks,

$A \quad$ is the cross-section of one rail $=6250 \mathrm{~mm}^{2}$.

From the known specific resistance of the earth electrode the rails, and from the known earthing resistance of the rails, the amount of stray currents outside the return conductor - the rails, can be calculated according to the following equation [3]:

$$
I_{b}=I_{t} \cdot\left(\frac{R_{t}}{R_{t}+R_{o}}\right)
$$

where:

$I_{b}$ is stray current in \%

$I_{t}$ is the current in the rails in \%

Let us take an example of a single track line where the electric traction vehicle is located in the middle of the section between both ENP (Fig. 1). In this case, the same amount of return current is flowing towards ENP 1 and towards ENP 2, which means that both ENP are equally loaded.

Suppose there is a very well maintained road metal with a specific resistance of $5000 \Omega \mathrm{m}$, which is laid on clay with a specific resistance of $50 \Omega \mathrm{m}$. The calculation gives the following results:

- the surface of the earthing electrode - the rails of a single line track is $7500 \mathrm{~m}^{2}$,

- the diameter of the equivalent circular earthing electrode is $98 \mathrm{~m}$,

- the specific resistance of rails over a distance of $30 \mathrm{~km}$ is 0.48 $\Omega / 30 \mathrm{~km}$

- earthing resistance of the earthing electrode - the rails is $0.7 \Omega$,

- the amount of stray currents is $41 \%$

It can be seen from the result that from the total current load of the electric traction vehicle, $59 \%$ of the current flows through the rails and $41 \%$ of the current is dispersed into the earth and then returns to the ENP along the paths of highest conductivity (pipelines, ...).

However, the amount of $41 \%$ is divided into two parts, one flowing towards ENP 1 and the other part towards ENP 2, which means that in the direction of one ENP there flows a stray current of only around $20 \%$ of the total current. The loading current of the new $6 \mathrm{MW}$ locomotive amounts to around $2000 \mathrm{~A}$ at full load, which means that in the directions of both ENP, $200 \mathrm{~A}$ of current is dissipated in the ground. But it is clear that this partition of stray currents is possible only at the moment when both ENP carry the same load. The more we are approaching ENP 2 the less current is flowing to ENP 1. As a consequence, ENP to which the electric traction vehicle is nearer is heavier loaded. But due to the shorter distance the amount of stray currents is lower. Less and less current is flowing towards the more distant ENP. The amount of stray currents is increasing but this amount is very small with regard to the minimal current in the rails. 
Hence it follows that the highest stray currents arise in the system of Slovenian railways, when the electric traction vehicle operates in the middle of the railway section between two ENP.

In the case of a double-track railway line having the same parameters of both the road metal and the basic earth as in a singletrack line there are $38 \%$ of stray currents outside the rails. Due to a greater number of rails in a double-track line the percentage of stray currents is lower.

Therefore, the actual amount of stray currents depends on the distance between the electric traction vehicle from the ENP and properties of the road metal and the earth.

Fig. 3 shows the amount of stray currents for a single-track and a double-track electrified railway line with a specific resistance of the road metal of $5000 \Omega \mathrm{m}$ and a specific resistance of the earth of $50 \Omega \mathrm{m}$.

$b(\%)$

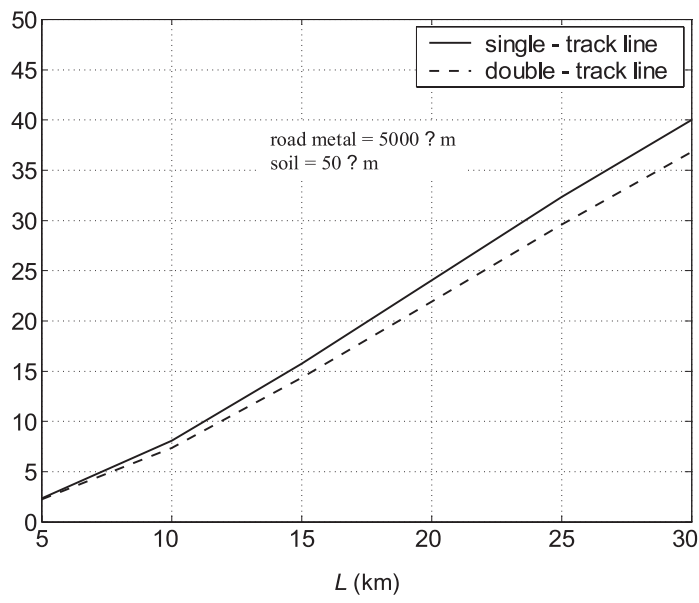

Fig. 3 The amount of stray currents in a direct current railway line at $3000 \mathrm{~V}$ with a specific crushed stone resistance of $5000 \Omega \mathrm{m}$ and a specific earth resistance of $50 \Omega \mathrm{m}$

It can be seen from Fig. 3 that with a growing distance between the electric traction vehicle and ENP the percentage of stray currents flowing through the road metal and the earth is increasing. At a distance of $20 \mathrm{~km}$ from ENP, the percentage of stray currents amounts to around $24 \%$ on a single-track line and to around $22 \%$ on a double-track line.

Fig. 4 shows the percentage of stray currents which is owing to higher earth resistance of $100 \Omega \mathrm{m}$ significantly lower and amounts to around $19 \%$ in a single-track line at a distance of $20 \mathrm{~km}$ from ENP, and to around $17 \%$ in a double-track line.

Figures 5 and 6 show the percentage of stray currents for earth of high specific resistance. In this case, the amount of stray currents is minimal.

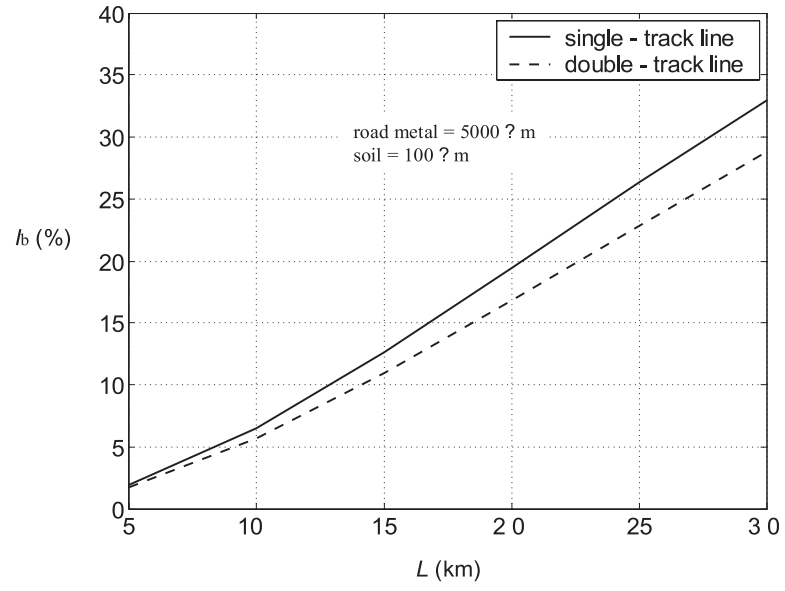

Fig. 4 The amount of stray currents in direct current railway at $3000 \mathrm{~V}$ with specific ballast resistance of $5000 \Omega \mathrm{m}$ and specific earth resistance of $100 \Omega \mathrm{m}$

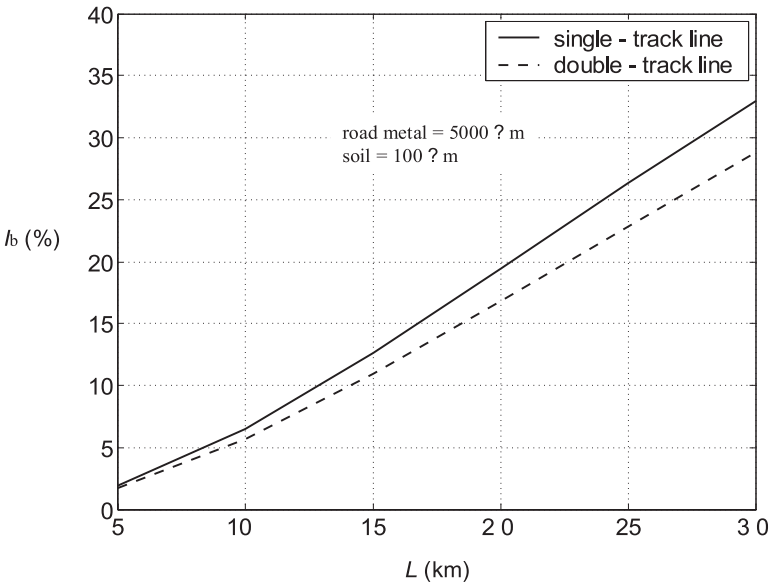

Fig. 5 The amount of stray currents in direct current railway at 3000 $V$ with specific crushed stone resistance of $5000 \Omega \mathrm{m}$ and specific ground resistance of $500 \Omega \mathrm{m}$

\section{Calculation of stray currents in direct current railway of $3000 \mathrm{~V}$ with the aid of the telegraphic equation}

The amount of stray currents in direct current railways can also be calculated according to the following equation [4]:

$$
I_{b}=I \cdot\left[1-\sqrt{1-t h \cdot\left(\frac{\alpha \cdot L_{t}}{2}\right)}\right](\%)
$$

where:

$I_{b}$ is the maximal value of stray currents in \%,

$I$ is $100 \%=$ the total current (current in the rail + stray current),

th is tan hyperbolic,

$L_{t}$ is the distance between the traction vehicle and ENP $(\mathrm{km})$

$\alpha$ is suppression factor of earth electrode - rails $\left(\mathrm{km}^{-1}\right)$ 


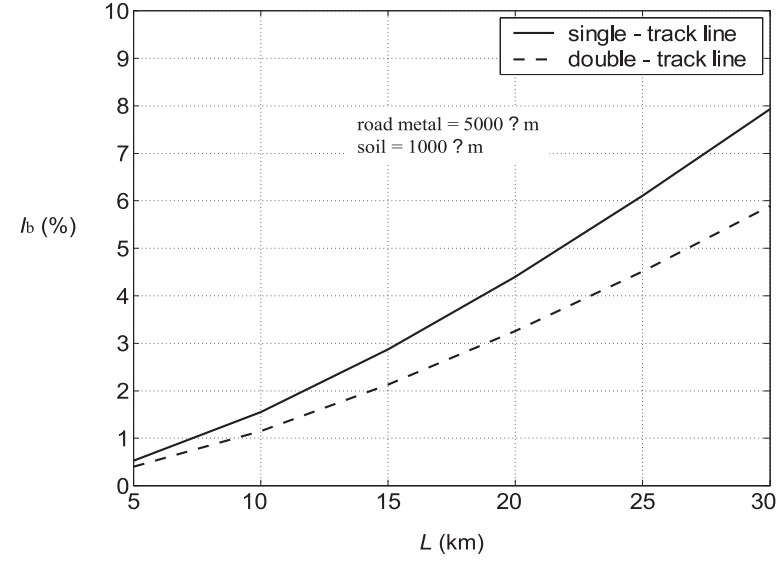

Fig. 6 The amount of stray currents in direct current railway at $3000 \mathrm{~V}$ with specific crushed stone resistance of $5000 \mathrm{\Omega m}$ and specific earth resistance of $1000 \Omega \mathrm{m}$

The equation for the suppression factor in direct current is derived from the following equation used for the constant of propagation of travelling waves in direct current [5]:

$$
\underline{\gamma}=\alpha+j \beta=\sqrt{(R+j \omega L) \cdot(G+j \omega C)}
$$

\section{where:}

$\gamma$ is propagation constant,

$\beta$ is rotation constant,

$L$ is inductivity,

C is capacity.

As there is no frequency in direct current, all the elements, except for resistance and conductivity, are omitted in the equation above. Thus, we arrive at the equation for the suppression factor of the straight-lined earthing electrode - the rails:

$$
\alpha=\sqrt{G \cdot R_{t}}\left(\mathrm{~km}^{-1}\right)
$$

where:

$G$ is the transversal conductance of the railway in $\mathrm{S} / \mathrm{km}$.

The transversal conductance of the railway is usually in the range from $0.1 \mathrm{~S} / \mathrm{km}$ and $5 \mathrm{~S} / \mathrm{km} \mathrm{[3].} \mathrm{The} \mathrm{cleaner} \mathrm{the} \mathrm{road} \mathrm{metal}$ and the smaller conductivity of the basic earth are, the lower the transversal conductance is. If there are very soiled and chemicalsoaked substratum and the basic earth of good conductivity, then the transversal conductance can be higher than $5 \mathrm{~S} / \mathrm{km}$. Let us consider the case of a single-track electrified railway where the electric traction vehicle is positioned at the middle of the railway section between two ENP (Fig. 1). Due to the fact that the return current is closed from the traction vehicle towards each ENP, the total length of the earthing electrode - the rails is $30 \mathrm{~km}$. First of all, we have to calculate the suppression factor of the straight-lined earthing electrode - the rails according to equation 8 , where it is supposed that the conductance of tracks is $0.1 \mathrm{~S} / \mathrm{km}$ and the resistance of rails is $0.016 \Omega / \mathrm{km}$ :

$$
\alpha=\sqrt{0.1 \cdot 0.48}=0.04 \mathrm{~km}^{-1}
$$

The percentage of stray currents in the earth is calculated according to equation 6 :

$$
I_{b}=100 \cdot\left(1-\sqrt{1-t h \cdot \frac{0.04 \cdot 30}{2}}\right)=53.7 \%
$$

The result indicates that $53.7 \%$ of the return current flows back to the ENP through the earth and not through the rails instead. Since the supply of the traction vehicle is from two sides, one half of these currents is divided between both ENP.

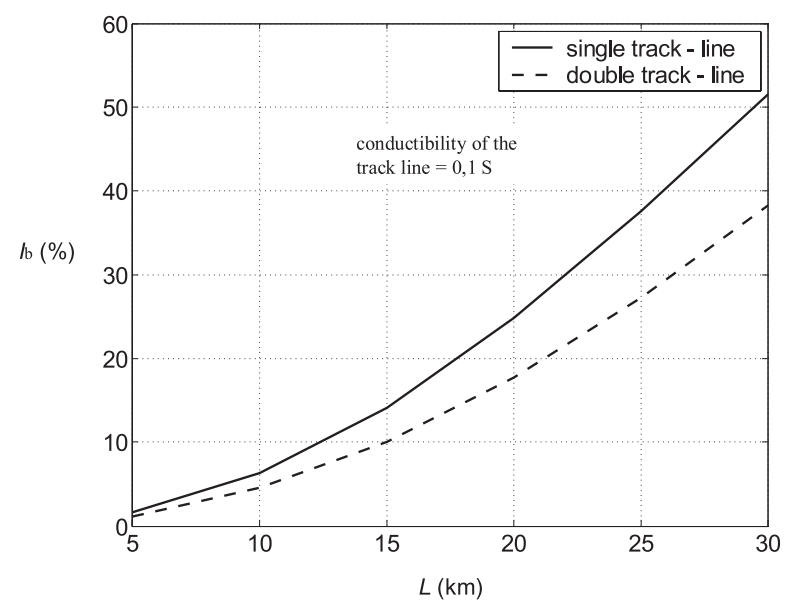

Fig. 7 The amount of stray currents in DC railway at $3000 \mathrm{~V}$ and the railway track conductivity of $0.1 \mathrm{~S}$

It can be seen in Fig. 7 that for the railway conductivity of 0.1 $\mathrm{S}$ at a distance of $20 \mathrm{~km}$ from the ENP on a single track railway, around $25 \%$ of the stray currents will flow outside the rails, and around $18 \%$ on a double track railway line.

\section{Simulation of stray currents in the Simulink program}

By means of the Matlab-Simulink program a very accurate simulation of DC stray currents can be carried out for a DC railway line using the following parameters [2]:

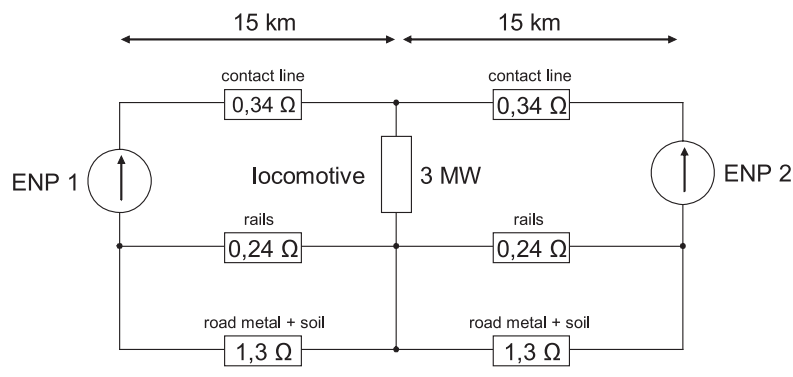

Fig. 8 Substitutional resistance model of single-track railway line 


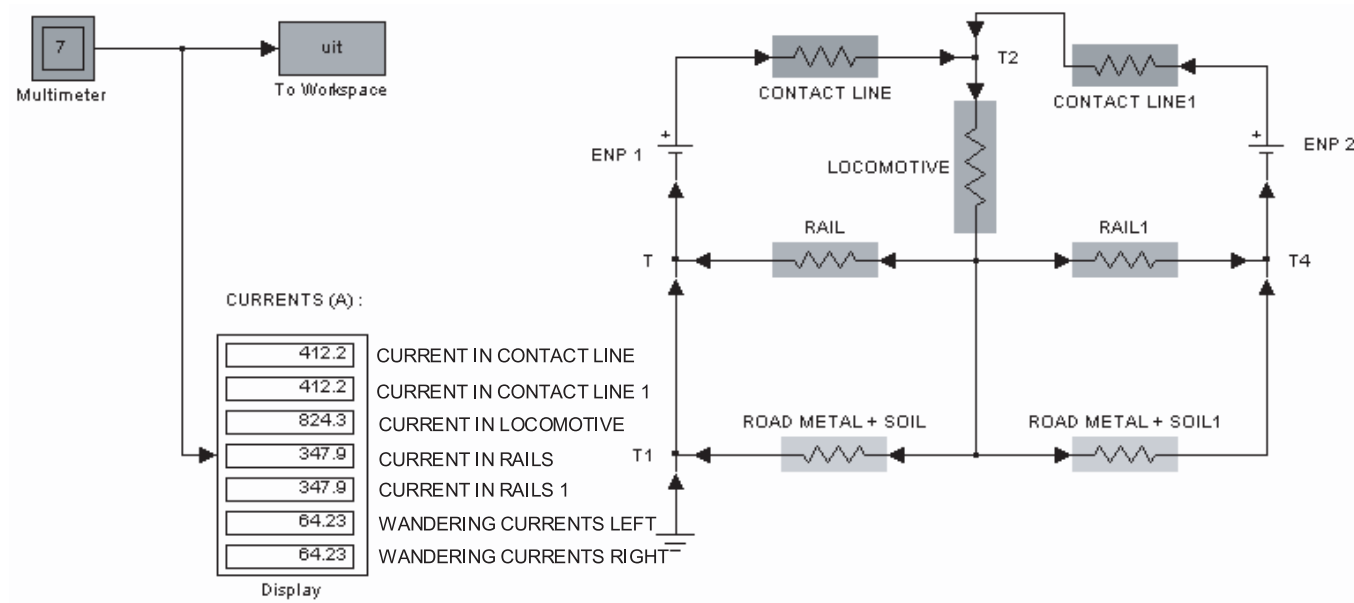

Fig. 9 Simulation scheme of stray currents on a DC railway in Simulink

- the distance between two ENP is $30 \mathrm{~km}$,

- the electric traction vehicle is positioned in the middle of the line section between both ENP,

- the power rating of the electric traction vehicle is $3 \mathrm{MW}$,

- the specific earth resistance is $50 \Omega \mathrm{m}$,

- the railway is a single-track line.

The substitutional resistance model of the single-track railway line based on calculations from Chapter 2, is shown in Fig. 8 [2]:

After performing the simulation the shown results are obtained on the simulation scheme in Fig. 9 [2]:

The total load current of the traction vehicle is $824.3 \mathrm{~A}$. The current of 347.9 A returns to ENP 1 and ENP 2 through rails, and 64.23 A through road metal and the earth. Total stray currents to ENP 1 and ENP 2 amount to around $20 \%$ over a distance of 15 $\mathrm{km}$, which means $40 \%$ for the total distance of $30 \mathrm{~km}$.

\section{Conclusion}

The paper presents an analysis of DC stray currents in direct current railways in Slovenia in three different ways. It is obvious that the results match considerably well. In addition to calculations and simulations, the measurements of DC stray currents are also possible:

- current measurements and

- measurements of the potential

However, owing to the dynamics of the electric traction, the measurements yield completely unreliable results. The loading current of the electric locomotive is varying at any given moment, depending on the profile of the track, the speed, etc. But on the other hand, the measurements represent a considerable cost, and owing to this fact, the measurements of this kind have never been carried out in Slovenia.

As a final result, the calculation is thoroughly satisfying for the analysis of stray currents in direct current railways. Due to varying values of ohmic resistances of earth and road metal over a long distance, the calculations can never produce exact results. However, these calculations are very useful for the design of electrified railways employing direct current system of $3000 \mathrm{~V}$. The mutual distance between two rectifier stations in new installations should be no more than $15 \mathrm{~km}$, which results in a considerable decrease in stray currents. The average distance between rectifier stations is $30 \mathrm{~km}$ in Slovenia now. Therefore, the Slovenian railways represent the greatest threat to different metal structures in the country.

\section{References}

[1] KOCH, W.: Grounds of Electrical Sevices under Tension above 1 kV - number 2 (in German), Verlag Julius Springer, Berlin-Gottingen-Heidelberg, 1955.

[2] CENE, B.: Modernization of Electric Traction on Slovene Railways (in Slovene) Master's work, Fakulteta za elektotehniko Maribor, 2004.

[3] CURK, F.: Problems of One-way Shaking Currents - I. part (in Slovene), Elektroinstitut Milan Vidmar, Ref. st. 594, Ljubljana, 1973.

[4] CENE, B.: Stray Currents on One-way Railway 3000 V (in Slovene), Individually research work, Fakulteta za elektotehniko Maribor, 2004.

[5] VORSIC, J., PIHLER, J.: Technology of High Tension (in Slovene), Fakulteta za elektotehniko Maribor, 1997. 